\title{
Half-volt operation of IGZO thin-film transistors enabled by ultrathin HfO2 gate dielectric
}

DOI:

$10.1063 / 1.5037410$

Document Version

Accepted author manuscript

Link to publication record in Manchester Research Explorer

\section{Citation for published version (APA):}

Ma, P., Sun, J., Liang, G., Li, Y., Xin, Q., Li, Y., \& Song, A. (2018). Half-volt operation of IGZO thin-film transistors enabled by ultrathin $\mathrm{HfO}$ gate dielectric. Applied Physics Letters, 113(6), [063501].

https://doi.org/10.1063/1.5037410

\section{Published in:}

Applied Physics Letters

\section{Citing this paper}

Please note that where the full-text provided on Manchester Research Explorer is the Author Accepted Manuscript or Proof version this may differ from the final Published version. If citing, it is advised that you check and use the publisher's definitive version.

\section{General rights}

Copyright and moral rights for the publications made accessible in the Research Explorer are retained by the authors and/or other copyright owners and it is a condition of accessing publications that users recognise and abide by the legal requirements associated with these rights.

\section{Takedown policy}

If you believe that this document breaches copyright please refer to the University of Manchester's Takedown Procedures [http://man.ac.uk/04Y6Bo] or contact uml.scholarlycommunications@manchester.ac.uk providing relevant details, so we can investigate your claim.

\section{OPEN ACCESS}




\title{
Half-Volt Operation of IGZO Thin-Film Transistors Enabled by Ultrathin $\mathrm{HfO}_{2}$ Gate Dielectric
}

\author{
Pengfei Ma, ${ }^{1}$ Jiamin Sun, ${ }^{1}$ Guangda Liang, ${ }^{1}$ Yunpeng Li, ${ }^{1}$ Qian Xin,,${ }^{1,2}$ Yuxiang Li, ${ }^{1 \text { a) }}$ and Aimin Song ${ }^{1}$ \\ 2,3 a) \\ ${ }^{I}$ Center of Nanoelectronics and School of Microelectronics, Shandong University, Jinan 250100, China \\ ${ }^{2}$ State Key Laboratory of Crystal Materials, Shandong University, Jinan 250100, China \\ ${ }^{3}$ School of Electrical and Electronic Engineering, University of Manchester, Manchester M13 9PL, United Kingdom
}

Amorphous indium-gallium-zinc oxide (a-IGZO) thin-film transistors (TFTs) enabled by an ultrathin, $5 \mathrm{~nm}, \mathrm{HfO}_{2}$ film grown by atomic-layer deposition were fabricated. An ultra-low operation voltage of $1 \mathrm{~V}$ was achieved by a very high gate capacitance of $1300 \mathrm{nF} / \mathrm{cm}^{2}$. The $\mathrm{HfO}_{2}$ layer showed excellent surface morphology with a low root-mean-square roughness of $0.20 \mathrm{~nm}$ and reliable dielectric properties, such as low leakage current and high breakdown electric field. As such, the a-IGZO TFTs exhibit desirable properties as low power devices, including a small subthreshold swing of $75 \mathrm{mV} /$ decade, a low threshold voltage of $0.3 \mathrm{~V}$, and a high on/off current ratio of $8 \times 10^{6}$. Furthermore, even under an ultralow operation voltage of $0.5 \mathrm{~V}$, the on/off ratio was also up to $1 \times 10^{6}$. The electron transport through the $\mathrm{HfO}_{2}$ layer has also been analyzed, indicating the Poole-Frenkel emission and Fowler-Nordheim tunneling mechanisms in different voltage ranges.

Recently, there are emerging applications of thin-film transistors (TFTs), such as wearables electronics $^{1}$, sensors ${ }^{2}$, and thin-film circuits ${ }^{3}$. However, these devices are challenged by limited battery lifetime, therefore low-voltage operations are highly desirable and even necessity. Among various TFTs channel materials, wide band gap oxide materials are naturally suited to batteryoperated electrics due to the very low off current. In 2004, Hosono et al. ${ }^{4}$ first reported roomtemperature fabrication of TFTs using amorphous indium-gallium-zinc oxide (a-IGZO). After that, a-IGZO has received much attention because of its excellent performance, including high electron mobility, low off current, excellent uniformity, surface flatness, stability, optical transparency, large-area production, and wide process temperature. ${ }^{5,6}$ As such, a-IGZO TFTs have started replacing amorphous-silicon transistors in large-area displays. ${ }^{7,8}$ However, large voltages are often needed for a-IGZO TFTs to achieve high mobility and high on/off current ratios.

To reduce the operation voltage of TFTs, large gate capacitance is a necessity. Reducing the thickness of gate dielectric layer is one of the methods to increase the capacitance, but the thickness reduction of the conventional $\mathrm{SiO}_{2}$ gate dielectric is limited by the tunneling current. Fortunately, using high-dielectric-constant (high- $k$ ) materials to replace $\mathrm{SiO}_{2}$ as gate layer can simultaneously enable a low leakage current and a low-voltage operation. Various high- $k$ materials, e.g., $\mathrm{Y}_{2} \mathrm{O}_{3}{ }^{4}$, $\mathrm{Al}_{2} \mathrm{O}_{3},{ }^{9,10} \mathrm{HfO}_{2},{ }^{2,11} \mathrm{Ta}_{2} \mathrm{O}_{5},{ }^{12} \mathrm{HoTiO}_{3},{ }^{13} \mathrm{HfLaO},{ }^{14,15} \mathrm{LaLuO}_{3},{ }^{16} \mathrm{LaAlO}_{3},{ }^{17}$ have been reported for aIGZO TFTs. However, for high- $k$ materials, there is a general phenomenon that the band gap decreases with the increase of the $k$ value. ${ }^{18}$ Therefore, to avoid a large leakage current, a high-

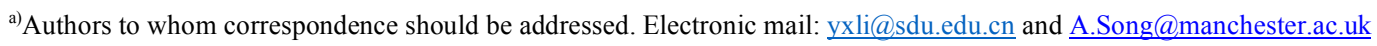


quality dielectric layer with a large enough band gap is necessary. Among these high- $k$ candidates, $\mathrm{Al}_{2} \mathrm{O}_{3}$ has a large band gap $\left(E_{\mathrm{g}}=8 \mathrm{eV}\right)$, and in our previous work we have demonstrated that ultrathin $\mathrm{Al}_{2} \mathrm{O}_{3}$ film can be a highly reliable dielectric in a-IGZO TFTs enabling a $1 \mathrm{~V}$ operation. ${ }^{19}$ However, the $k$ value of $\mathrm{Al}_{2} \mathrm{O}_{3}$ is only $\sim 9.0$. Robertson et al. reviewed different high- $k$ materials. ${ }^{18}$ They pointed out that among various high- $k$ materials, $\mathrm{HfO}_{2}$ and $\mathrm{Hf}$-silicate are preferred oxide due to the high enough $k$ value $(k=20 \sim 25)$, thermal stability, kinetic stability, and low bulk defect density. ${ }^{18}$ Chun et al. also proposed that $\mathrm{HfO}_{2}$ and $\mathrm{HfO}_{2}$-based materials are the most promising gate dielectrics. ${ }^{20} \mathrm{HfO}_{2}$-based high- $k$ materials have been employed as a gate dielectric since $45 \mathrm{~nm}$ CMOS logic circuits in the industry. ${ }^{21-24}$ In this work, due to the large $k$ value, the IGZO TFTs enabled by an ultrathin $5 \mathrm{~nm} \mathrm{HfO}_{2}$ gate dielectric are able to operate at $0.5 \mathrm{~V}$, half that of our previous work. ${ }^{19}$ Importantly, $\mathrm{HfO}_{2}$ has thicker physical thickness than $\mathrm{Al}_{2} \mathrm{O}_{3}$ for the same capacitance or the same equivalent oxide thickness (EOT), which can suppress the leakage current significantly. The thicker dielectric makes the TFTs much more stable and reliable, and is much more desirable than $5 \mathrm{~nm} \mathrm{Al} \mathrm{O}_{3}$ considering substrate roughness. The $\mathrm{HfO}_{2}$ film is usually grown by atomic-layer deposition (ALD) which can precisely control the film thickness with angstrom precision. However, very thin gate dielectrics have been found to show different dielectric properties from thick ones. ${ }^{19,25,26}$ So, it is worth exploring the characteristics of devices based on ultrathin high- $k$ materials.

In this work, a-IGZO TFTs with an ultrathin $5 \mathrm{~nm} \mathrm{HfO}_{2}$ layer as the gate dielectric were fabricated. The $\mathrm{HfO}_{2}$ films were grown by ALD at $150{ }^{\circ} \mathrm{C}$ using alternating precursors of tetrakis (ethylmethylamino) hafnium (TEMAH) and $\mathrm{H}_{2} \mathrm{O}$ vapor at a deposition rate of approximately 0.11 $\mathrm{nm}$ per cycle. The carrier gas was $\mathrm{N}_{2}$ and the pressure in chamber was 0.02 Torr during the deposition. The 5-nm $\mathrm{HfO}_{2}$ film has been experimented to explore possible use in a-IGZO TFTs. We are able to show that even an ultrathin $5 \mathrm{~nm} \mathrm{HfO}_{2}$ film can be a highly reliable dielectric. The obtained TFTs exhibit excellent properties for low-voltage operations, including a small subthreshold swing $(S S)$, a low threshold voltage $\left(V_{\mathrm{T}}\right)$, a high mobility $(\mu)$, and a high on/off current ratio $\left(I_{\mathrm{on}} / I_{\mathrm{off}}\right)$. In particular, our a-IGZO TFTs can be operated at an extremely low voltage of half volt. This is, to the best of our knowledge, the lowest operating voltage reported to date, which may have useful implications for wearables or other low-power electronics based on thin film technology.

A schematic structure of the fabricated a-IGZO TFTs is shown in Fig. 1(a). A $5 \mathrm{~nm} \mathrm{HfO} 2$ layer was grown by ALD on an n-type heavily doped $\mathrm{Si}\left(\mathrm{n}^{+}-\mathrm{Si}\right)$ wafer. By using radio-frequency (RF) sputtering technology, a 10-nm a-IGZO was deposited through a shadow mask at room temperature to form the active layer. The fraction ratio of the $\mathrm{In}_{2} \mathrm{O}_{3}: \mathrm{Ga}_{2} \mathrm{O}_{3}: \mathrm{ZnO}$ target is $1: 1: 1 \mathrm{~mol}$. \%. The RF sputtering power and Ar pressure were maintained at $90 \mathrm{~W}$ and 3.65 mTorr, respectively. Finally, Al source and drain contact electrodes were formed by thermal evaporation through a shadow mask. The active channel length $(L)$ and channel width $(W)$ of TFTs are 60 and $2000 \mu \mathrm{m}$, respectively. Upon completion of the contacts deposition, the devices were coated with a $400 \mathrm{~nm}$ PMMA (950 $\mathrm{K}, 4.5 \mathrm{wt} . \%$ ) layer and then annealed in air at $150{ }^{\circ} \mathrm{C}$ for $0.5 \mathrm{~h}$ in order to reduce oxygen vacancies in a-IGZO film and suppress the $\mathrm{H}_{2} \mathrm{O}$ adsorption. ${ }^{5,19}$ The capacitive properties of the $\mathrm{HfO}_{2}$ gate 
dielectric were investigated by metal-insulator-semiconductor ( $\mathrm{MIS}, \mathrm{Al} / \mathrm{HfO}_{2} / \mathrm{p}$ - $\mathrm{Si}$ ) capacitors prior to a-IGZO TFTs fabrication. These devices were characterized by capacitance-voltage $(C-V)$ and current-voltage (I-V) measurements using an E4980A Precision LCR Meter and Agilent B2900 Precision Source/Measure Unit (SMU). For a better understanding of the vertical carrier transport mechanism (related to leakage current), we applied large voltages to the $\mathrm{MIS}\left(\mathrm{Al} / \mathrm{HfO}_{2} / \mathrm{n}^{+}-\mathrm{Si}\right)$ capacitors and fitted the leakage current curves by different modes. To further confirm the quality of $\mathrm{HfO}_{2}$ layer, we investigated the surface morphology of the $\mathrm{HfO}_{2}$ film by atomic-force microscopy (AFM).

(a)

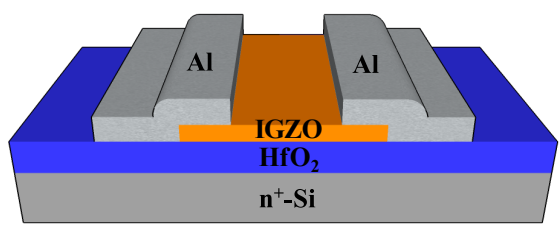

(c)

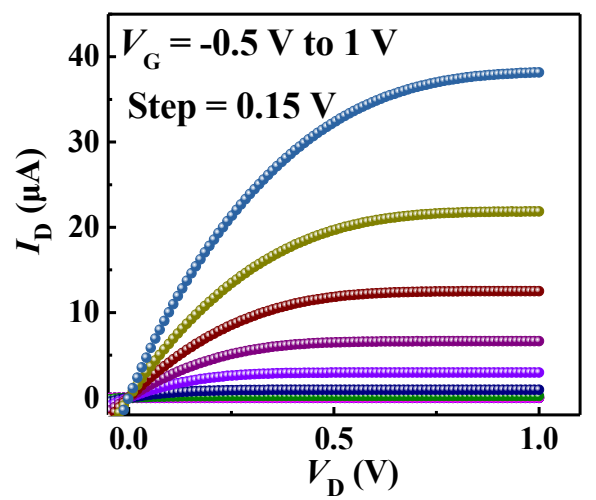

(b)
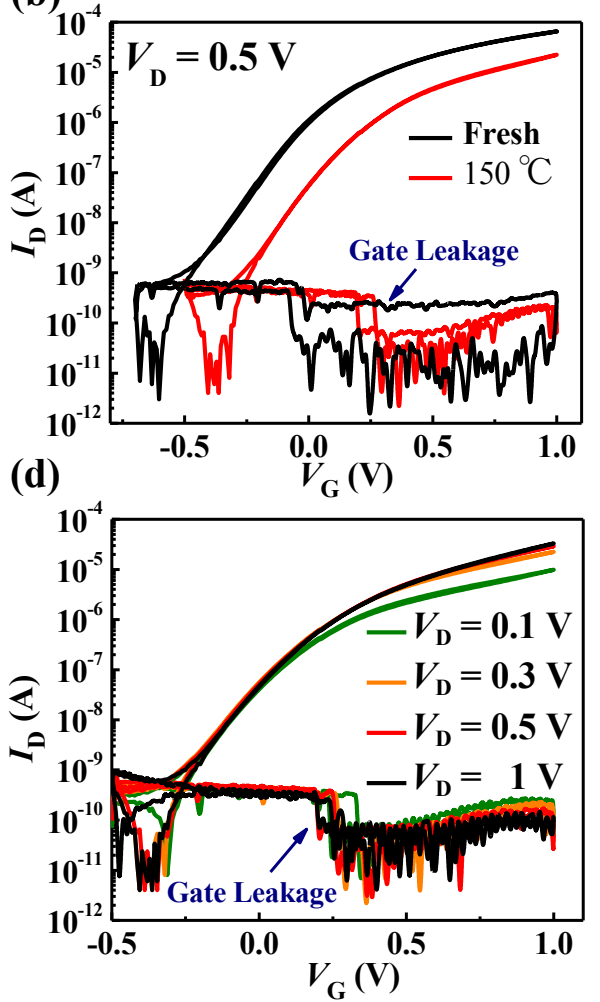

Fig. 1. (a) Schematic diagram of the a-IGZO TFTs. (b) Transfer characteristics of device before and after thermal

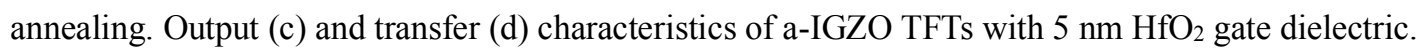

Figure 1(b) shows the transfer characteristics of device before and after thermal annealing. The as-fabricated device could operate under $1 \mathrm{~V}$ with a large on/off ratio. However, the device needs to be turned off at a gate voltage of $-0.7 \mathrm{~V}$. Unlike chemically ALD-deposited $\mathrm{HfO}_{2}$ films, sputteredIGZO films often have unbalanced stoichiometry due to the high-energy ion bombardment. ${ }^{19}$ In general, oxide films deposited through sputtering contain a large number of oxygen vacancies causing a high conductivity. Thermal annealing in air is an effective method to reduce such vacancies. ${ }^{5}$ After annealing treatment, $V_{\mathrm{T}}$ was found to shift to $0.3 \mathrm{~V}$ as shown in Fig. 1(b), which indicates that oxygen vacancies in the a-IGZO film were reduced efficiently. The experimental results at different temperatures (not shown here) revealed that $150{ }^{\circ} \mathrm{C}$ was the optimum annealing temperature for maintaining a good carrier mobility and high on/off ratio. Furthermore, very little hysteresis is observed in the drain current versus gate voltage $\left(I_{\mathrm{D}}-V_{\mathrm{G}}\right)$ transfer curve. This indicates that no significant mobile charges are present and that the density of slow interface traps is low, confirming a high quality of $\mathrm{HfO}_{2}$ dielectric. ${ }^{17}$ Figure 1 (c) shows the output characteristics of an a- 
IGZO TFT with a $5 \mathrm{~nm} \mathrm{HfO}_{2}$ gate dielectric after $150{ }^{\circ} \mathrm{C}$ annealing treatment, exhibiting a welldefined pinch-off behavior. Figure 1(d) shows the transfer characteristics of a-IGZO TFTs with 5 $\mathrm{nm} \mathrm{HfO}_{2}$ gate dielectric under different drain voltages after $150{ }^{\circ} \mathrm{C}$ thermal annealing. The TFTs exhibit desirable properties including a low threshold voltage of $0.3 \mathrm{~V}$, a small subthreshold swing of $75 \mathrm{mV} /$ decade, and a high on/off current ratio of $8 \times 10^{6}$. The low $S S$ value in the $5 \mathrm{~nm} \mathrm{HfO}_{2}$ TFT is a result of the large gate capacitance. Importantly, we have realized $1 \mathrm{~V}$ operation of our aIGZO TFTs by using the ultrathin $5 \mathrm{~nm} \mathrm{HfO}_{2}$ dielectric layer.

(a)

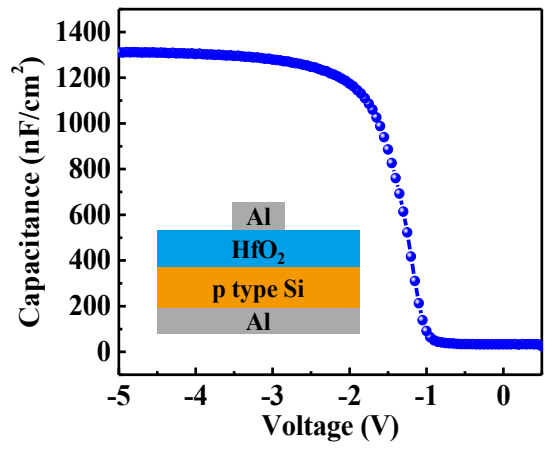

(b)

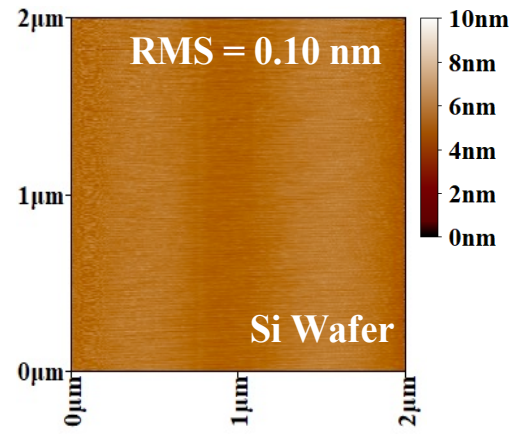

(c)

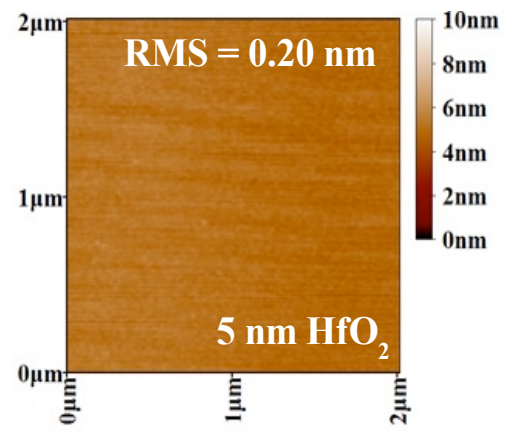

Fig. 2. (a) $C-V$ characteristics and schematic diagram (inset) of an $\mathrm{Al} / \mathrm{HfO}_{2}(5 \mathrm{~nm}) / \mathrm{p}$-Si MIS capacitor. AFM images of the (b) Si Wafer and (c) $5 \mathrm{~nm} \mathrm{HfO} 2$ film.

For TFT devices, large gate capacitance is very crucial to reduce the operation voltage. Researchers have showed that the properties of ultrathin gate dielectrics may be different from thick ones. ${ }^{25,26}$ The accurate value of gate dielectric capacitance $\left(C_{\mathrm{ox}}\right)$ plays a vital part in the calculation of carrier mobility and interface trap density $\left(N_{\mathrm{t}}\right)$, and thus MIS capacitors were made to confirm the capacitance of the thin $\mathrm{HfO}_{2}$ layer. Figure 2(a) and the inset show the $C-V$ characteristics and schematic cross-sectional view of an $\mathrm{Al} / \mathrm{HfO}_{2}(5 \mathrm{~nm}) / \mathrm{p}-\mathrm{Si}$ capacitor, respectively. A very high capacitance of $C_{\mathrm{ox}}=1300 \mathrm{nF} / \mathrm{cm}^{2}$ is determined, and this is capacitance of an equivalent $\mathrm{SiO}_{2}$ dielectric of $2.6 \mathrm{~nm}$. Such a thin $\mathrm{SiO}_{2}$ dielectric, however, would be vulnerable to leakage current.

The performance of a-IGZO TFTs is known to directly associate with the interfacial quality between gate dielectrics and channel layer. The $5 \mathrm{~nm} \mathrm{HfO}_{2}$ dielectric film shows excellent surface morphology with a very low root-mean-square (RMS) roughness of $0.20 \mathrm{~nm}$ as shown by the AFM image in Fig. 2(c). The surface morphology of the Si substrate (RMS $=0.1 \mathrm{~nm}$ ) is shown in Fig. 2(b). In addition, the quality of gate dielectric can also be manifested by the TFT subthreshold swing. Under $1 \mathrm{~V}$ operation voltage, the $5 \mathrm{~nm} \mathrm{HfO}$-based a-IGZO TFT exhibits a very low $S S$ of $75 \mathrm{mV} /$ decade, which is quite desirable to turn on the transistor effectively at low voltages. Furthermore, a high mobility $\mu$ of $4.6 \mathrm{~cm}^{2} / \mathrm{Vs}$ was achieved. The extremely small hysteresis in Figs. 1(b) and (d) indicate very low $N_{\mathrm{t}}$ at the gate dielectric interface, which also correlates well with the low $\mathrm{HfO}_{2}$ surface roughness. The value of $N_{\mathrm{t}}$ can be determinate by:

$$
S S=\frac{k_{\mathrm{B}} T \ln 10}{q}\left[1+\frac{q^{2}}{C_{\mathrm{ox}}} N_{\mathrm{t}}\right]
$$


where $k_{\mathrm{B}}$ is Boltzmann's constant, $T$ is the temperature in Kelvin, and $q$ is the electron charge.

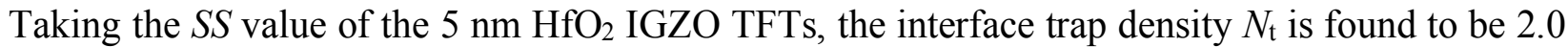
$\times 10^{12} \mathrm{eV}^{-1} \mathrm{~cm}^{-2}$, which is among the lowest values in reported $\mathrm{HfO}_{2}$ TFTs to date. ${ }^{27,28}$

The reproducibility and uniformity are challengeable for IGZO TFTs with such ultrathin gate dielectrics. Only a slight defect on the substrate or in the gate insulator should deteriorate the gate leakage current. We have repeated our experiments and fabricated a-IGZO TFTs on three $\mathrm{n}^{+}-\mathrm{Si}$ substrates (denoted as Samples A, B and C, respectively). We selected six TFTs on each sample randomly. The transfer curves of these devices are shown in Figure S1. From the graph our TFTs show good reproducibility and uniformity. The statistical distributions of a-IGZO TFTs characteristics of three samples are summarized in Table SI.

(a)

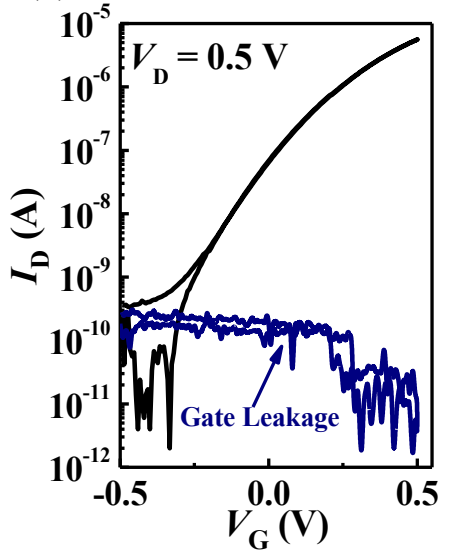

(b)

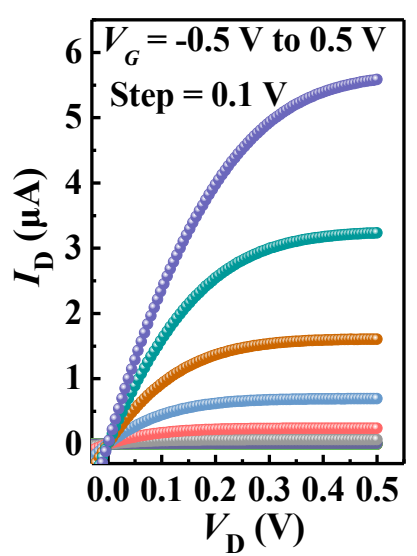

Fig. 3. Transfer (a) and output (b) characteristics of a-IGZO TFTs with $5 \mathrm{~nm} \mathrm{HfO}_{2}$ gate dielectric layer under $0.5 \mathrm{~V}$ operation voltage.

We further tested the TFTs based on $5 \mathrm{~nm} \mathrm{HfO}_{2}$ under lower operation voltages. Figures. 3(b) and (c) show the transfer and output characteristics of a-IGZO TFTs under $0.5 \mathrm{~V}$ operation voltage. A high $I_{\mathrm{on}} / I_{\mathrm{off}}$ ratio and well-behaved transistor output characteristics were still achieved. The mobility is $1.5 \mathrm{~cm}^{2} / \mathrm{Vs}$, somewhat lower than that at $1 \mathrm{~V}\left(4.6 \mathrm{~cm}^{2} / \mathrm{Vs}\right)$. This is not unusual because carrier trapping by interface states becomes more dominated at low gate voltages. ${ }^{19}$ Importantly, even under such low operation voltage, the on current is still about 6 orders of magnitude higher than the off current.

TABLE I. Comparison of our a-IGZO TFTs with those in the literature with different gate dielectrics.

\begin{tabular}{|c|c|c|c|c|c|c|}
\hline $\begin{array}{c}\text { Gate } \\
\text { dielectrics }\end{array}$ & $\begin{array}{c}T_{0 x} \\
(n m)\end{array}$ & $\begin{array}{l}V_{\mathrm{ON}} \\
(\mathrm{V})\end{array}$ & $\begin{array}{l}V_{\mathrm{T}} \\
(\mathrm{V})\end{array}$ & $\begin{array}{c}S S \\
(\mathrm{mV} / \mathrm{dec})\end{array}$ & $\begin{array}{c}\mu \\
\left(\mathrm{cm}^{2} / \mathrm{Vs}\right)\end{array}$ & $I_{\mathrm{on}} / I_{\mathrm{off}}$ \\
\hline $\mathrm{Al}_{2} \mathrm{O}_{3}{ }^{9}$ & 100 & 5 & 0.4 & 100 & 8 & $6 \times 10^{7}$ \\
\hline $\mathrm{HfO}_{2}{ }^{2}$ & 60 & 0.8 & 0.2 & 90 & 5.9 & $2.4 \times 10^{7}$ \\
\hline $\mathrm{HoTiO}_{3}{ }^{13}$ & 60 & 8 & 0.1 & 160 & 21.4 & $1.3 \times 10^{8}$ \\
\hline $\mathrm{HfLaO}^{15}$ & 40 & 1.5 & 0.1 & 180 & 22.1 & $2 \times 10^{5}$ \\
\hline $\mathrm{LaLuO}_{3}{ }^{16}$ & 20 & 2 & 0.3 & 310 & 6.6 & $1 \times 10^{3}$ \\
\hline $\mathrm{HfO}_{2}{ }^{11}$ & 20 & 2 & 0.2 & 109 & 8.1 & $1 \times 10^{7}$ \\
\hline $\mathrm{LaAlO}_{3}{ }^{17}$ & 15.5 & 1.4 & 0.4 & 68 & 4.1 & $1 \times 10^{5}$ \\
\hline
\end{tabular}




\begin{tabular}{ccccccc}
$\mathrm{Al}_{2} \mathrm{O}_{3}{ }^{19}$ & 5 & 1 & 0.3 & 100 & 6.3 & $1.2 \times 10^{7}$ \\
\hline (This & $\mathbf{5}$ & $\mathbf{0 . 5}$ & $\mathbf{0 . 1}$ & $\mathbf{7 5}$ & $\mathbf{1 . 5}$ & $\mathbf{1} \times \mathbf{1 0}^{\mathbf{6}}$ \\
work) & $\mathbf{5}$ & $\mathbf{1}$ & $\mathbf{0 . 3}$ & $\mathbf{7 5}$ & $\mathbf{4 . 6}$ & $\mathbf{8} \times \mathbf{1 0}^{\mathbf{6}}$
\end{tabular}

In Table I, we have compared the key device parameters of our a-IGZO TFTs with previously reported devices in which the thickness of gate dielectric $\left(T_{\mathrm{ox}}\right)$ is thinner than $100 \mathrm{~nm}$. $V_{\mathrm{ON}}$ represents the operation voltage. Our devices show the lowest operating voltages in oxide semiconductor TFTs, which is favorable for wearables or other low-power electronics based on thin-film technology.

(a)

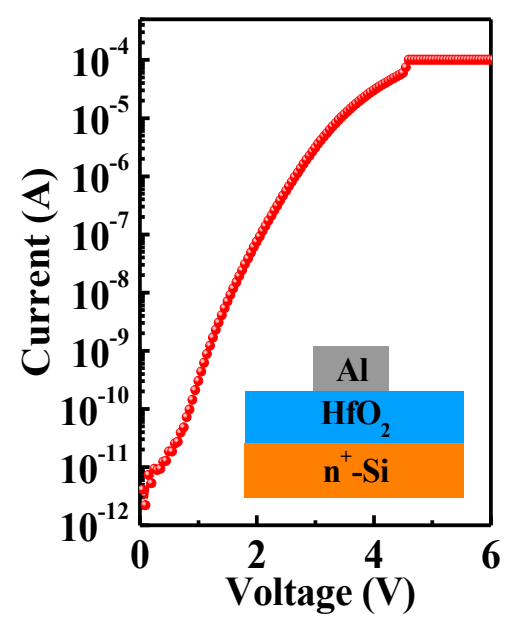

(b)

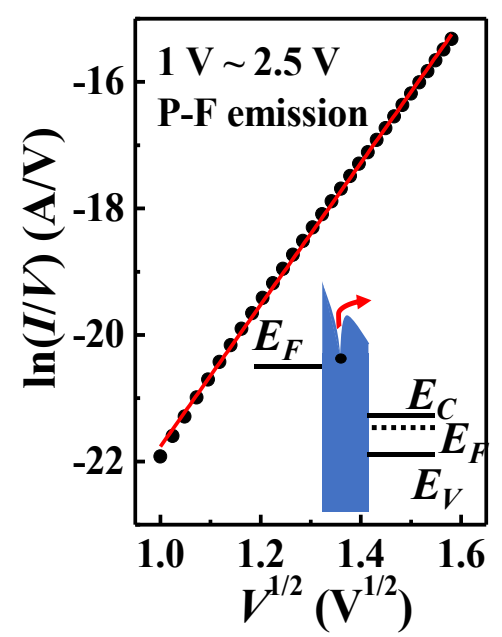

(c)

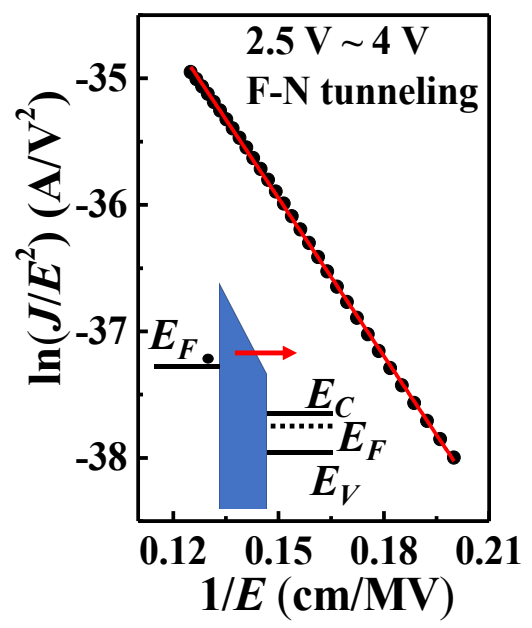

Fig. 4. (a) Breakdown tests (main graph) and schematic diagram (inset) of for $\mathrm{Al} / \mathrm{HfO}_{2} / \mathrm{n}^{+}-\mathrm{Si}$ MIS devices with 5 $\mathrm{nm} \mathrm{HfO}_{2}$ layer. The liner fitting for leakage current by (b) P-F emission and (c) F-N tunneling models.

To test the robustness of the 5-nm-thin $\mathrm{HfO}_{2}$ and for deep analysis of the vertical carrier transport mechanism (related to leakage current), we applied large voltages to the MIS ( $\left.\mathrm{Al} / \mathrm{HfO}_{2} / \mathrm{n}^{+}-\mathrm{Si}\right)$ capacitors and fitted the leakage current curve by different modes. The breakdown voltage of $5 \mathrm{~nm}$ $\mathrm{HfO}_{2}$ is found to be about $4.5 \mathrm{~V}$ as shown in Fig.4 (a). The breakdown electric field strength is comparable to other reports about $\mathrm{HfO}_{2}{ }^{29,30}$ There are a few possible electron transport mechanisms including direct tunneling, Poole-Frenkel (P-F) emission, Fowler-Nordheim (F-N) tunneling, and Schottky emission, etc.

The P-F emission is due to emission of trapped electrons into the conduction band. The $I-V$ curves follow

$$
I \propto V \exp \left[\frac{q}{k_{\mathrm{B}} T}\left(2 a \sqrt{V}-\phi_{o}\right)\right]
$$

where $a$ is a constant, $\phi_{o}$ is the barrier height. ${ }^{31}$

The F-N tunneling current is given by

$$
\frac{J}{E^{2}}=C_{1} e^{-C_{2} / E}
$$


where $J$ is the current density and $E$ is the electric field across the oxide. $\mathrm{C}_{1}$ and $\mathrm{C}_{2}$ are given by

$$
\begin{aligned}
& \mathrm{C}_{1}=q^{3} m / 16 \pi^{2} \hbar m_{\mathrm{ox}} \phi_{\mathrm{o}} \\
& \mathrm{C}_{2}=\frac{4}{3} \frac{\left(2 m_{\mathrm{ox}}\right)^{1 / 2}}{q \hbar} \phi_{\mathrm{o}}^{\frac{3}{2}}
\end{aligned}
$$

where $m$ and $m_{\mathrm{ox}}$ are the electron mass in free space and in the oxide, respectively, and $2 \pi \hbar$ is Planck's constant. ${ }^{32}$

Figures 4 (b) and (c) show linear fittings of $5 \mathrm{~nm} \mathrm{HfO} 2$ leakage current according to Eq. 2 in the low voltage range (1-2.5 V) and Eq. 3 in the high voltage range (2.5-4 V), respectively. The dotted lines are the experiment results and the red solid lines are the fittings. Other transport models do not provide such a good agreement. The inset images in Figs. 4 (b) and (c) are schematic energyband diagrams showing conduction mechanisms of P-F emission and F-N tunneling. The fitting results indicate that under a lower $E$, most carriers get through the films via shallow traps, and when $E$ is strong enough, the carriers can obtain enough energy and tunnel through the barrier.

In summary, a-IGZO TFTs enabled by an ultrathin $5 \mathrm{~nm} \mathrm{HfO}_{2}$ gate dielectric have been demonstrated to be capable of operating not only at $1 \mathrm{~V}$ but also even at half volt. Importantly, TFTs also exhibit other desirable properties including negligible hysteresis, a steep subthreshold slope, and high $I_{\mathrm{on}} / I_{\text {off }}$ ratio. We also discovered that the $5 \mathrm{~nm}$-thin $\mathrm{HfO}_{2}$ layer showed excellent surface morphology and good dielectric properties. The breakdown voltage of the $\mathrm{HfO}_{2}$ film is as high as $4.5 \mathrm{~V}$ and the electron transport mechanisms through the $\mathrm{HfO}_{2}$ layer have been analyzed. The results indicate that the half-volt operation of the a-IGZO TFTs may have a great promise for future wearables or other low-power electronics.

This work was financed by the National Key Research and Development Program of China (Grant Nos. 2016YFA0201800 and 2016YFA0301200), the National Natural Science Foundation of China (Grant Nos. 11374185, 11304180 and 11374182), Engineering and Physical Sciences Research Council (EPSRC) (Grant No. EP/N021258/1), China Postdoctoral Science Foundation (2015M582073 and 2016M590634), the Natural Science Foundation of Shandong Province (ZR2013EMQ011), the Natural Science Foundation of Jiangsu Province (BK20151255), Suzhou Planning Projects of Science and Technology (SYG201527 and SYG201616), and the Fundamental Research Funds of Shandong University (2013TB008, 2014QY005 and 2016WLJH44).

\section{References}

1 Y. S. Rim, S.-H. Bae, H. Chen, N. De Marco, and Y. Yang, Adv. Mater. 28, 4415-4440 (2016).

2 C.-H. Lu, T.-H. Hou, and T.-M. Pan, IEEE Trans. Electron Devices 63, 5060-5063 (2016).

3 J. I. Leon, S. Kouro, L. G. Franquelo, J. Rodriguez, and B. Wu, IEEE Trans. Ind. Electron. 63, 2688-2701 (2016).

4 K. Nomura, H. Ohta, A. Takagi, T. Kamiya, M. Hirano, and H. Hosono, Nature 432, 488-492 (2004). 
B. Zhang, H. Li, X. Zhang, Y. Luo, Q. Wang, and A. Song, Appl. Phys.Lett. 106, 093506 (2015). L. Du, H. Li, L. Yan, J. Zhang, Q. Xin, Q. Wang, and A. Song, Appl. Phys.Lett. 110, 011602 (2017).

7 S. Nakano, N. Saito, K. Miura, T. Sakano, T. Ueda, K. Sugi, H. Yamaguchi, I. Amemiya, M. Hiramatsu, and A. Ishida, Journal of the Society for Information Display 20, 493-498 (2012).

8 J.-h. Lee, D.-h. Kim, D.-j. Yang, S.-y. Hong, K.-s. Yoon, P.-s. Hong, C.-o. Jeong, H.-s. Park, S. Y. Kim, S. K. Lim, S. S. Kim, K.-s. Son, T.-s. Kim, J.-y. Kwon, S.-y. Lee, and Sid, SID Symposium Digest of Technical Papers 39, 625-628 (2008).

9 J. B. Kim, C. Fuentes-Hernandez, W. J. Potscavage, X. H. Zhang, and B. Kippelen, Appl. Phys.Lett. 94, 142107 (2009).

10 C. H. Wu, K. M. Chang, S. H. Huang, I. C. Deng, C. J. Wu, W. H. Chiang, and C. C. Chang, IEEE Electron Device Lett. 33, 552-554 (2012).

11 Y. Shao, X. Xiao, X. He, W. Deng, and S. D. Zhang, IEEE Electron Device Lett. 36, 573-575 (2015).

12 C. J. Chiu, S. P. Chang, and S. J. Chang, IEEE Electron Device Lett. 31, 1245-1247 (2010).

13 T.-M. Pan, C.-H. Chen, J.-H. Liu, J.-L. Her, and K. Koyama, IEEE Electron Device Lett. 35, 66-68 (2014).

14 N. C. Su, S. J. Wang, and A. Chin, IEEE Electron Device Lett. 30, 1317-1319 (2009).

15 S. Nai-Chao, W. Shui-Jinn, H. Chin-Chuan, C. Yu-Han, H. Hao-Yuan, C. Chen-Kuo, and A. Chin, IEEE Electron Device Lett. 31, 680-682 (2010).

${ }^{16}$ I. C. Kun, H. Hsiao-Hsuan, C. Chun-Hu, L. Kai-Yu, L. Shang-Rong, and A. Chin, IEEE Conference on Electron Devices Solid-State Circuits, 1-2 (2013).

17 C. H. Cheng, K. I. Chou, and H. H. Hsu, J. Nanosci. Nanotechnol. 15, 1486-1489 (2015).

18 J. Robertson and R. M. Wallace, Mater. Sci. Eng. R 88, 1-41 (2015).

19 P. Ma, L. Du, Y. Wang, R. Jiang, Q. Xin, Y. Li, and A. Song, Appl. Phys. Lett. 112, 023501 (2018).

20 Z. Chun, C. Z. Zhao, M. Werner, S. Taylor, and P. R. Chalker, ISRN Nanotechnology 2012, 689023 (2012).

${ }^{21}$ H. Huey-liang, C. W. Wang, K. H. Chang, C. H. Tsai, K. C. Leou, C.-L. Kuei-Shu, L. ChunChang, S. C. Chang, F. C. Chiu, C. H. Liu, A. Chin, C. Kow-Ming, and C. Bwo-Ning, IEEE Int. Conf. Electron Devices Solid-State Circuits 7, 1-5 (2008).

22 C. B. Oh, H. S. Kang, H. J. Ryu, M. H. Oh, H. S. Jung, Y. S. Kim, J. H. Lee, N. I. Lee, K. H. Cho, D. H. Lee, T. H. Yang, I. S. Cho, H. K. Kang, Y. W. Kim, and K. P. Suh, IEDM, 423-426 (2002).

23 P. D. Kirsch, J. H. Sim, S. C. Song, S. Krishnan, J. Peterson, H. J. Li, M. Quevedo-Lopez, C. D. Young, R. Choi, N. Moumen, P. Majhi, Q. Wang, J. G. Ekerdt, G. Bersuker, and B. H. Lee, Proc. Eur. Solid-State Device Res. Conf., 367-370 (2005).

${ }^{24}$ H. R. Huff, A. Hou, C. Lim, Y. Kim, J. Barnett, G. Bersuker, G. A. Brown, C. D. Young, P. M. Zeitzoff, J. Gutt, P. Lysaght, M. I. Gardner, and R. W. Murto, Microelectron. Eng. 69, 152-167 (2003).

25 M. D. Groner, J. W. Elam, F. H. Fabreguette, and S. M. George, Thin Solid Films 413, 186-197 (2002).

26 A. Daus, C. Vogt, N. Munzenrieder, L. Petti, S. Knobelspies, G. Cantarella, M. Luisier, G. A. Salvatore, and G. Troster, IEEE Trans. Electron Devices 64, 2789-2796 (2017).

27 R. Z. Wang, S. L. Wu, X. Y. Li, and J. T. Zhang, Solid-State Electron. 133, 6-9 (2017). 
${ }^{28}$ L. Yuan, X. Zou, G. Fang, J. Wan, H. Zhou, and X. Zhao, IEEE Electron Device Lett. 32, 4244 (2011).

29 R. Thamankar, F. M. Puglisi, A. Ranjan, N. Raghavan, K. Shubhakar, J. Molina, L. Larcher, A. Padovani, P. Pavan, S. J. O'Shea, and K. L. Pey, J. Appl. Phys. 122, 024301 (2017).

30 T.-L. Shih, Y.-H. Su, T.-C. Kuo, W.-H. Lee, and M. I. Current, Appl. Phys. Lett. 111, 012101 (2017).

31 Y. Takahashi and K. Ohnishi, IEEE Trans. Electron Devices 40, 2006-2010 (1993).

32 M. Lenzlinger and E. H. Snow, J. Appl. Phys. 40, 278-283 (1969). 